\title{
Characterizing Sexual Behavior in Frontotemporal Dementia
}

\author{
Rebekah M. Ahmed ${ }^{\mathrm{a}, \mathrm{b}, \mathrm{e}, \mathrm{g}, 1}$, Cassandra Kaizik $^{\mathrm{a}, 1}$, Muireann $\operatorname{Irish}^{\mathrm{a}, \mathrm{d}, \mathrm{e}}$, Eneida Mioshi $^{\mathrm{f}}$, \\ Nadene Dermody ${ }^{\mathrm{a}, \mathrm{d}}$, Matthew C. Kiernan ${ }^{\mathrm{g}}$, Olivier Piguet ${ }^{\mathrm{a}, \mathrm{c}, \mathrm{e}}$ and John R. Hodges ${ }^{\mathrm{a}, \mathrm{c}, \mathrm{e}, *}$ \\ ${ }^{a}$ Neuroscience Research Australia, Sydney, Australia \\ ${ }^{\mathrm{b}}$ Prince of Wales Clinical School, The University of New South Wales, Sydney, Australia \\ ${ }^{\mathrm{c}}$ School of Medical Sciences, The University of New South Wales, Sydney, Australia \\ ${ }^{\mathrm{d}}$ School of Psychology, The University of New South Wales, Sydney, Australia \\ e ARC Centre of Excellence in Cognition and its Disorders, The University of New South Wales, Sydney, Australia \\ ${ }^{\mathrm{f}}$ Department of Psychiatry, University of Cambridge, Cambridge, UK \\ ${ }^{\mathrm{g}}$ Sydney Medical School, Brain \& Mind Research Institute, University of Sydney, Australia
}

Handling Associate Editor: Marc Sollberger

Accepted 13 March 2015

\begin{abstract}
.
Background: Frontotemporal dementia (FTD) is characterized by a number of prominent behavioral changes. While FTD has been associated with the presence of aberrant or unusual sexual behaviors in a proportion of patients, few studies have formally investigated changes in sexual function in this disease.

Objective: We aimed to systematically quantify changes in sexual behavior, including current symptoms and changes from prior diagnoses, in behavioral-variant (bvFTD) and semantic dementia (SD), compared to Alzheimer's disease (AD).

Methods: Carers of 49 dementia patients (21 bvFTD, 11 SD, 17 AD) were interviewed using the Sexual Behavior and Intimacy Questionnaire (SIQ), a survey designed to assess changes in sexual function across multiple domains including initiating, level of affection, and aberrant or unusual sexual behavior.

Results: BvFTD patients show prominent hyposexual behavior including decreased affection, initiation, and response to advances by partners, and decreased frequency of sexual relations, compared to AD and to SD patients. The greatest changes in sexual behavior compared to pre-diagnoses were found in the bvFTD group with a 90-100\% decrease in initiation, response, and frequency of sexual relations. Notably, aberrant or unusual sexual behavior was reported in a minority of bvFTD and SD patients and occurred in patients who also showed hyposexual behavior toward their partner.

Conclusion: Overall loss of affection, reduced initiation of sexual activity, and responsiveness is an overwhelming feature of bvFTD. In contrast, aberrant or unusual sexual behavior is observed in the minority of bvFTD patients. The underlying pathophysiology of these changes likely reflects structural and functional changes in frontoinsular and limbic regions including the hypothalamus.
\end{abstract}

Keywords: Alzheimer's disease, frontotemporal dementia, sexual function

\section{INTRODUCTION}

Frontotemporal dementia (FTD) is the second most common cause of young-onset dementia $[1,2]$ and is

\footnotetext{
${ }^{1}$ These authors contributed equally to this work.

*Correspondence to: Professor John Hodges, Neuroscience Research Australia, Barker Street, Randwick NSW 2031, Australia. Tel.: +61 29399 1000; Fax: +61 29399 1047; E-mail: j.hodges@ neura.edu.au.
}

associated with pervasive changes in behavior and personality. Characteristic changes include alterations in eating [3, 4], emotion processing [5], and sleeping [6]. Disinhibition is commonly reported in the behavioral variant of FTD (bvFTD) [7] and has led to the assumption that bvFTD patients exhibit hypersexual behavior. Perhaps surprisingly, there has been little examination of sexual function in bvFTD, other than isolated reports [8-10] and series [11, 12] using retrospective case 
note analyses, documenting hypersexuality and aberrant behaviors in a proportion of cases. One previous study that used a carer survey suggested that hyposexuality may be the dominant behavioral change [13]. Despite this, the limited evidence to date has led to the conclusion that hypersexuality and aberrant behavior is a common behavioral manifestation of bvFTD.

In other forms of dementia including Alzheimer's disease (AD), sexual function has been examined with findings that included a gradual decline in interest, while affection toward their partner was maintained [14]. A small percentage of AD patients show hypersexuality [15].

Given the limited evidence regarding sexual function in FTD, we aimed to systematically explore sexual behavior in the FTD subtypes of bvFTD and semantic dementia (SD), including aspects of sexual initiation and affection, symptoms of hypersexuality, or of aberrant sexual behavior, and to compare these to a cohort of $\mathrm{AD}$ patients. The $\mathrm{AD}$ group was used for comparison as changes in sexual interest and activity are not typically reported in this syndrome. The SD group were included as behavioral changes similar to bvFTD are often reported in SD patients. As such, investigation of changes in sexual behavior could potentially serve as a useful clinical tool in the differentiation of FTD syndromes, and in the management of behavioral symptoms typically seen in these disorders. We hypothesized, based upon pilot observations, that a small proportion of FTD patients, particularly bvFTD, would show hypersexuality and/or aberrant sexual behavior, but the majority would show signs of hyposexuality, that is, decreased interest in affection and sexual intimacy with their partner. We further sought to explore the relationship between changes in sexual function in dementia syndromes and aspects of socioemotional wellbeing such as empathy and motivation. Characterizing the changes in sexual function in FTD has the potential to reveal important insights into the underlying pathophysiological and neuroendocrine abnormalities in this syndrome.

\section{MATERIALS AND METHODS}

\section{Patients}

Forty-nine dementia patients (21 bvFTD; 11 SD: 2 right variant, 9 left; 17 AD) were recruited from FRONTIER, the frontotemporal dementia clinic at Neuroscience Research Australia, Sydney Australia. All patients underwent a comprehensive assessment, which included a clinical interview, neurological examination, cognitive testing, and structural brain MRI. All patients met the current clinical diagnostic criteria for probable bvFTD, SD, or AD [16-19]. Disease severity was established using the Frontotemporal Dementia Rating Scale (FRS) [20]. The FRS provides logit scores which are subdivided into six categories, ranging from very mild, to profound. Higher scores denote higher functional ability. Carers also completed the Cambridge Behavioral Inventory (CBI) [21], the Interpersonal Reactivity Index (IRI), a standardized questionnaire of empathy [22], and the Neuropsychiatric Inventory (NPI) [23]. Timing of symptom onset was an estimate provided by the caregiver. Patients underwent extensive neuropsychological testing including the Addenbrooke's Cognitive Examination (ACE- R) [24]. Exclusion criteria included significant extrapyramidal features, past history of stroke, epilepsy, alcoholism, or significant traumatic brain injury. Patients with an uncertain diagnosis, or where a partner who had an intimate relationship with the patient was not available, were also excluded from the project.

\section{Concomitant diseases and medications}

Patients' records from their local medical officer were obtained to ascertain presence of other conditions that may affect sexual behavior. Caregivers were also asked about possible contributing physical medical problems that would affect sexual function, e.g., long-standing sexual dysfunction, and these patients were excluded. No patients were on dopamine agonist treatment.

\section{Assessment of sexual behavior}

A modified version of the Sexual Behavior and Intimacy Questionnaire (SIQ) (Supplementary File 1), a survey designed to identify changes in sexual behavior in FTD, by comparing their premorbid behavior and interests to their current status, was administered to all caregivers who were also the intimate partner of the patient in a face-to-face interview by the same clinician (CK). The SIQ was developed combining aspects of a number of existing sexual function surveys and validated tools [25-27].

The SIQ requires partners to rate the frequency of a behavior on a 5-point Likert scale, ranging from 0 (Almost never/Never) to 5 (Almost Always/Always), across the following domains: 1) initiating and responding to general affection; 2) initiating and responding to sexual intimacy; and 3) frequency of 
Table 1

Demographic characteristics and cognitive scores for the dementia groups

\begin{tabular}{|c|c|c|c|c|c|}
\hline & $\mathrm{AD}$ & bvFTD & SD & $\mathrm{F}$ value & Post hoc test \\
\hline Gender (F:M) & $6: 11$ & $7: 14$ & $6: 5$ & $3.9(2)$ & NA \\
\hline Age $(y)$ & $64.4 \pm 7.9$ & $64.8 \pm 8.2$ & $66.7 \pm 6.5$ & $0.34(2)$ & NA \\
\hline Mean education (y) & $12.3 \pm 0.6$ & $12.5 \pm 0.3$ & $12.6 \pm 0.4$ & $2.2(2)$ & NA \\
\hline Disease duration $(\mathrm{y})$ & $5.8 \pm 4.6$ & $5.8 \pm 3.4$ & $5.7 \pm 1.9$ & $0.002(2)$ & NA \\
\hline ACE-R total $(100$, normal $>88)$ & $62 \pm 17$ & $76 \pm 16$ & $60 \pm 19$ & $* 4.6(2)$ & bvFTD $>$ AD, SD \\
\hline CBI abnormal behaviors & $4.9 \pm 5.2$ & $10.1 \pm 5.4$ & $7.2 \pm 5.8$ & *4.4 (2) & bvFTD > AD \\
\hline NPI total score & $10.4 \pm 11.1$ & $31.2 \pm 16.5$ & $17.7 \pm 10.2$ & $* * * 11.4(2)$ & bvFTD $>$ AD, SD \\
\hline FRS Rasch score & $-0.04 \pm 1.5$ & $-0.98 \pm 1.1$ & $0.71 \pm 1.6$ & $* * 5.8(2)$ & bvFTD $<$ SD \\
\hline
\end{tabular}

Data presented as mean \pm standard deviation (degrees of freedom). ${ }^{*} p<0.05 ;{ }^{* *} p<0.01 ;{ }^{* * *} p<0.001$; NS, not significant; N/A, not applicable; ACE-R, Addenbrookes cognitive examination revised; CBI, Cambridge behavioral inventory; NPI, neuropsychiatric inventory; FRS, Frontal rating scale.

sexual activity. The SIQ also records the development of any aberrant or unusual sexual behaviors or interests, which were not present previously, including change in sexual activities they wish to engage in, sexual interest in another person, disinhibited or childish behavior concerning sex, or a new interest in pornography, voyeurism, chat lines, or prostitutes. Partners were also asked whether changes occurred before or after the onset of other dementia symptoms. Caregivers were asked to rate the effect of changes in patient behavior overall on their relationship on a scale ranging from -10 to +10 . A score of 0 indicated no effect, while a negative score indicated a negative effect, and a positive score a positive effect. Scores were then classified as either no effect, positive, or negative.

\section{Standard protocols approvals, registrations, and patients consents}

This study was approved by the South Eastern Sydney and Illawarra Area Health Service and the University of New South Wales human ethics committees. Written informed consent was obtained from the participant and/or primary caregiver.

\section{Data analysis}

Data were analyzed using IBM SPSS statistics (version 21.0). Kolmogorov-Smirnov tests were run to determine suitability of variables for parametric analyses. Analyses of variance (ANOVA), followed by Tukey post hoc tests, were used to explore main effects of group (bvFTD, SD, and AD) for age and total ACE scores $(p<0.05$ regarded as significant). The presence of each survey variable and changes in behavior was analyzed using Chi squared tests and post-hoc Fischer exact tests. Given the number of comparisons conducted, we used a more stringent threshold of $p<0.01$ to guard against Type I error.
Spearman correlations were also carried out to examine the relations between measures of motivation (apathy), abnormal and stereotypical behavior on the CBI, empathy on the IRI (subscores of perspective taking and empathetic concern), and initiating and responding to general affection, initiating, and responding to sexual intimacy and frequency of sexual activity on the SIQ. As above, to control for multiple comparisons, $p<0.01$ was regarded as significant in the correlation analyses. Measures of aberrant or unusual sexual behavior were correlated with measures of disinhibition as rated by caregivers on the NPI.

\section{RESULTS}

All groups were well matched for age, education, gender, and disease duration (all $p$ values $>0.1$ ) (Table 1). The bvFTD group had a lower FRS score $(p=0.006)$ compared to the SD group and demonstrated higher levels of overall cognitive function on the ACE-R compared to SD $(p=0.04)$ and $\mathrm{AD}(p=0.04)$ patients. The bvFTD patients displayed higher levels of abnormal behavior on the CBI relative to the AD group $(p=0.02)$. Further, bvFTD patients scored significantly higher overall on the NPI, relative to AD $(p<0.001)$ and SD $(p=0.03)$ patients.

\section{Sexual initiation and affection}

The percentages of patients showing particular behaviors in the domains of sexual initiation and affection are shown in Table 2. Group differences were found in the domains of patients behaving affectionately toward their partners, initiating and responding to sexual initiatives, and in the frequency of sexual relations with their partner. Compared to $\mathrm{AD}$, bvFTD patients showed decreased affectionate behavior $(p=0.005)$, initiation $(p=0.007)$, and response $(p=0.009)$ to sexual initiatives, and 
Table 2

Features of sexual initiation and affection $(\%)$

\begin{tabular}{|c|c|c|c|c|c|}
\hline & $\mathrm{AD}$ & bvFTD & SD & Chi-square & Post Hoc \\
\hline \multicolumn{6}{|c|}{ Behave affectionately toward partner } \\
\hline Almost never/seldom & 18 & 70 & 27 & *18.4 (8) & bvFTD $<$ AD \\
\hline Sometimes & 23 & 10 & 27 & & \\
\hline Often/always & 59 & 20 & 46 & & \\
\hline \multicolumn{6}{|c|}{ Like to receive affection from partner } \\
\hline Almost never/seldom & 18 & 50 & 9 & $12.1(8)$ & \\
\hline Sometimes & 12 & 15 & 36 & & \\
\hline Often/always & 70 & 35 & 55 & & \\
\hline \multicolumn{6}{|l|}{ Initiate sexual relations } \\
\hline Almost never/seldom & 59 & 94 & 55 & $* 15.3(8)$ & bvFTD $<$ AD \\
\hline Sometimes & 23 & 0 & 9 & & \\
\hline Often/always & 18 & 6 & 36 & & \\
\hline \multicolumn{6}{|c|}{ Respond to sexual initiatives from partner } \\
\hline Almost never/seldom & 44 & 82 & 10 & $* * 27.4(8)$ & bvFTD $<\mathrm{AD}, \mathrm{SD}$ \\
\hline Sometimes & 0 & 0 & 30 & & \\
\hline Often/Always & 56 & 18 & 60 & & \\
\hline \multicolumn{6}{|c|}{ Frequency of sexual relations with partner } \\
\hline Not at all/very rarely & 59 & 83 & 60 & $* 17.6(8)$ & bvFTD $<\mathrm{AD}, \mathrm{SD}$ \\
\hline Sometimes & 18 & 0 & 10 & & \\
\hline Regularly/very frequently & 23 & 17 & 30 & & \\
\hline
\end{tabular}

${ }^{*} p<0.05,{ }^{* *} p<0.01$, (degrees of freedom); values represent $\%$ of patients within each group.

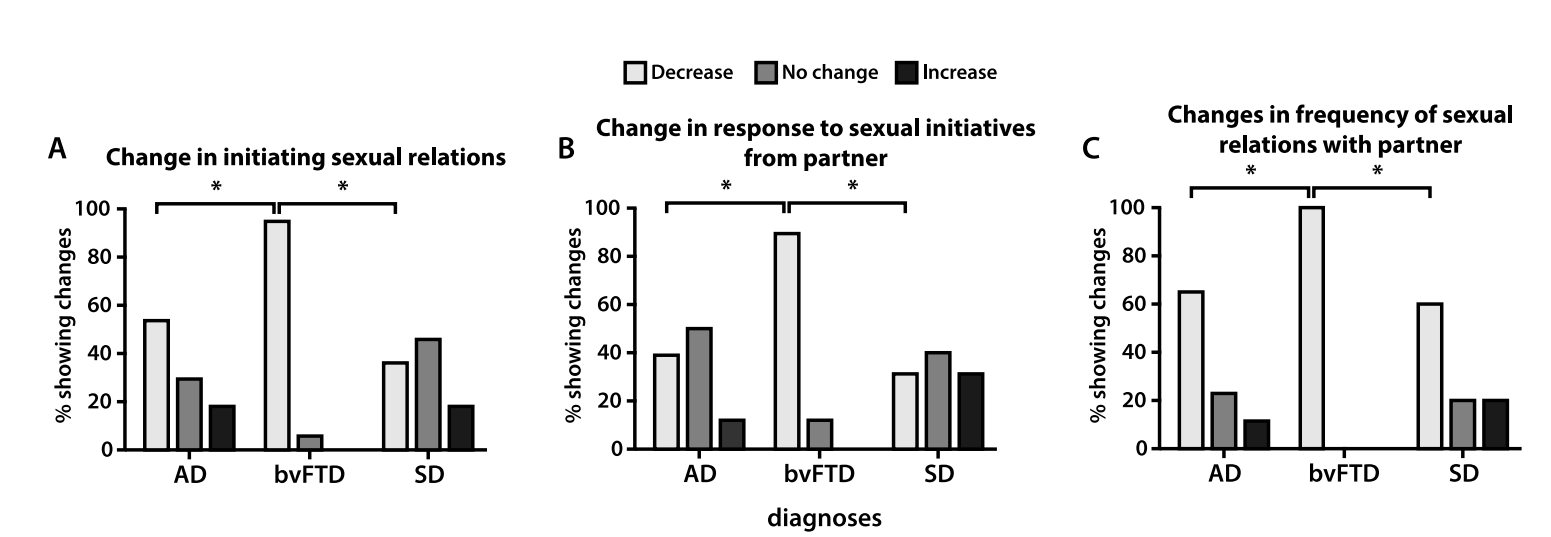

Fig. 1. Changes in sexual initiation, response, and frequency from prior to symptom onset and currently. A) Change in initiating sexual relations. ${ }^{*}$ bvFTD $>$ AD, SD $p<0.01$; B) Change in response to sexual initiatives *bvFTD $>$ AD, SD $p<0.01$; C) Change in frequency of sexual relations with partner *bvFTD $>$ AD, SD $p<0.01$.

decreased frequency of sexual relations $(p=0.010)$. The bvFTD group also exhibited decreased response to sexual initiatives $(p<0.001)$ and decreased frequency of sexual relations $(p=0.010)$ compared to the SD group. No group differences were observed between the $\mathrm{SD}$ and $\mathrm{AD}$ groups (all $p$ values $>0.21$ ).

\section{Change in sexual initiation and affection}

Results of changes in sexual initiation and affection from prior to disease onset and current state are shown in Figs. 1 and 2. BvFTD patients showed the greatest change with decreases evident across all domains, most notably in initiating sexual relations, responding to sexual initiatives from their partner, and frequency of sexual relations compared to the $\mathrm{AD}$ and SD groups (all $p$ values $<0.01$ ). Over $90 \%$ of partners of bvFTD patients reported a change in the initiation of sexual relations and response to initiatives compared to $<50 \%$ in the other two groups, with $100 \%$ reporting a change in the frequency of sexual relations. As shown in Fig. 2, $80 \%$ of the bvFTD group were less affectionate toward their partners, versus $60 \%$ in $\mathrm{SD}$ and $40 \%$ in $\mathrm{AD}(p=0.104)$. In terms of receiving affection, $65 \%$ of the bvFTD group showed a decrease in liking to receive affection versus only $46 \%$ in SD and $12 \%$ in the AD group $(p=0.320)$. 
$\square$ Decrease $\square$ Nochange $\square$ Increase
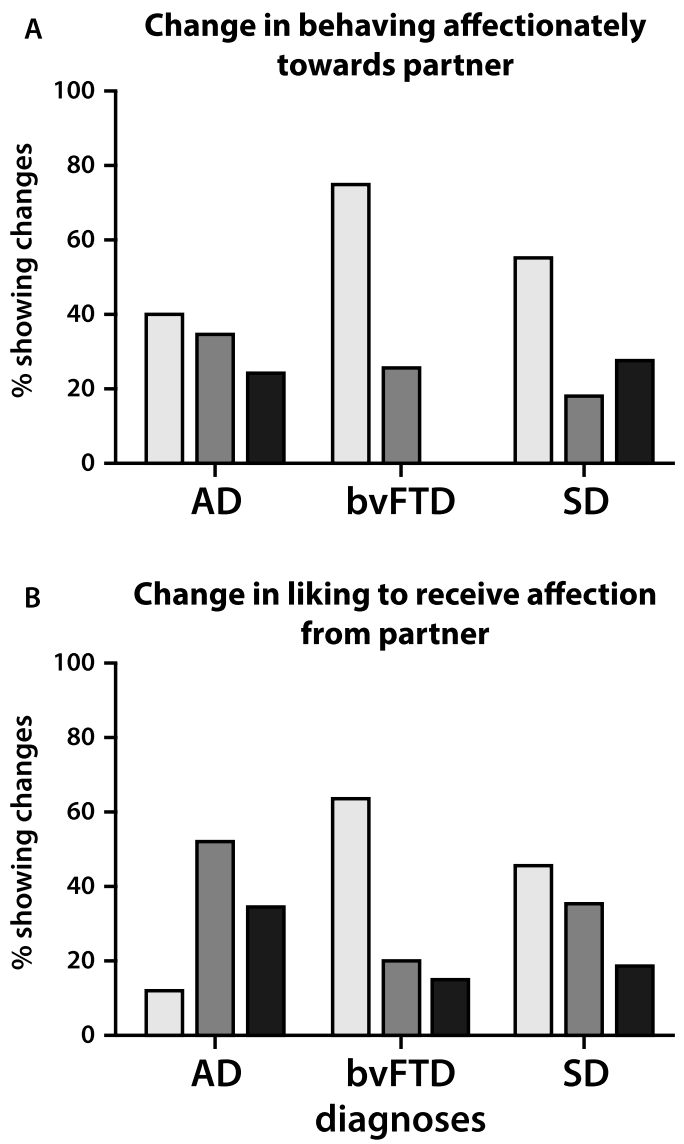

Fig. 2. Change in affection between patient and partner. A) Changes in behaving affectionately toward partner; B) Change in liking to receive affection from partner.

\section{Aberrant or unusual sexual behavior}

The frequencies of aberrant or unusual sexual behavior are shown in Table 3. Group differences were evident for changes in sexual activities $(p=0.03)$. SD patients $(n=3,27 \%$; 1 right variant, 2 left) showed the greatest change in activities that they wished to engage in compared to the AD and bvFTD groups $(p<0.01)$, including changes in behaviors around sexual relations with their partner. Patients who exhibited a sexual interest in another person $(n=2,10 \%)$ and a new interest in pornography, voyeurism, chat lines, and prostitutes $(n=3,14 \%)$ were only found in the bvFTD group and did not reach statistical significance. Only one AD patient exhibited aberrant behavior in the form of disinhibition and childish remarks regarding sex. All aberrant symptoms were new in onset and were not present premorbidly. Interestingly, the bvFTD patients that showed aberrant behavior did not show an increased frequency of initiating or responding to sexual relations with their partner, but directed their sexual preferences toward external sources. An illustrative case is described below.

\section{Case study}

A 52-year-old man presented with a 4-year history of behavioral change. Changes included inability to manage finances, binge eating, and decreased empathy, with a profound lack of insight. Following investigations, he received a diagnosis of probable bvFTD [17]. On the SIQ, his wife rated a significant change in her husband's 1) initiation of affection (from a rating of always to a rating of seldom), 2) response to affection from his wife (from always to never), 3) initiation of sexual relations (from always to never), and 4) response to sexual initiatives from wife (from always to never). The frequency of sexual relations had declined from a rating of sometimes to never. She reported that he had become more childish and disinhibited regarding sex, making sexual jokes to family

Table 3

Incidence of symptoms of aberrant sexual behavior

\begin{tabular}{|c|c|c|c|c|c|}
\hline & $\mathrm{AD}$ & bvFTD & $\mathrm{SD}$ & Chi-square & Posthoc \\
\hline \multicolumn{6}{|c|}{ Changes in sexual activities that your partner wishes to engage in? } \\
\hline Agree/Strongly agree & 0 & 5 & 27 & *13.8 (8) & $\mathrm{SD}>$ bvFTD and AD \\
\hline Disagree/Strongly disagree & 100 & 95 & 73 & & \\
\hline \multicolumn{6}{|c|}{ Developed a sexual interest in another person } \\
\hline Agree/Strongly agree & 0 & 10 & 0 & $4.3(8)$ & \\
\hline Disagree/Strongly disagree & 100 & 90 & 100 & & \\
\hline \multicolumn{6}{|c|}{ Become more disinhibited or childish about sex? } \\
\hline Agree/Strongly agree & 6 & 29 & 9 & $9.9(6)$ & \\
\hline Disagree/Strongly disagree & 94 & 71 & 91 & & \\
\hline \multicolumn{6}{|c|}{ Developed an interest in pornography, voyeurism, chat lines or prostitutes? } \\
\hline Agree/Strongly agree & 0 & 14 & 0 & $4.2(4)$ & \\
\hline Disagree/Strongly disagree & 100 & 86 & 100 & & \\
\hline
\end{tabular}

${ }^{*} p<0.05$ 
members and flirting with women, for example commenting on appearance and body size, both of which were uncharacteristic. He had developed an interest in online pornography approximately 2 years prior, and she was aware he was masturbating while viewing this material. He had allowed his son to see him watching pornographic material and left it visible on his iPad in view of his young daughter. Restrictions had to be placed on the household online devices to prevent access to pornography. His wife rated the impact of these changes in affection and sexual behavior as profoundly negative. She reported that the decline in her husband's sexual interest in her had initially been attributed to depression, which he was diagnosed and treated for 4 years prior. His wife reported feeling very neglected and that the changes in sexual behavior and interest had been very damaging.

\section{Caregiver rating of overall effect of change in sexual behavior on relationship}

There was no difference between the groups in terms of caregivers ratings of overall effect of changes in sexual behavior on their relationship $\left(\chi^{2}=5.3 ; p=0.254\right)$. The majority of patients rated changes in sexual behavior as having no effect on their relationship (61\% bvFTD, $63 \% \mathrm{SD}, 63 \% \mathrm{AD})$. In the bvFTD group, $39 \%$ of caregivers rated changes as having a negative effect and $0 \%$ as changes having a positive effect. In the SD caregiver group, $12 \%$ rated changes as having a negative effect and $25 \%$ as a positive effect. In the $\mathrm{AD}$ caregiver group, $25 \%$ felt changes had a negative effect versus $12 \%$ feeling there was a positive effect.

\section{Onset of sexual symptoms}

In the bvFTD group, 4 of the 21 caregivers $(19 \%)$ reported changes in sexual function prior to cognitive/behavioral symptom onset, versus 4 of the 17 carers in $\mathrm{AD}(24 \%)$ and 1 of 11 carers in the SD group (9\%).

\section{Correlations}

Exploring further the relationships between sexual behavior and abnormal behavior, we found that overall decreased affection $\left(r_{s}=-0.421, p=0.003\right)$, decreased response to affection $\left(r_{s}=-0.387\right.$, $p=0.007)$, decreased initiation $\left(r_{s}=-0.389, p=0.008\right)$ and responsiveness $\left(r_{s}=-0.481, p=0.008\right)$, and frequency of sexual relations $\left(r_{s}=-0.392, p=0.008\right)$ correlated with decreased levels of motivation on the CBI. Similarly, frequency of sexual relations $\left(r_{s}=0.533, p=0.005\right)$ and response to affection $\left(r_{s}=0.486, p=0.010\right)$ correlated with empathy scores (empathic concern) on the IRI. Decreased affection $\left(r_{s}=-0.383, p=0.007\right)$ and decreased response to affection $\left(r_{s}=-0.400, p=0.005\right) \quad$ correlated to increased abnormal behavior subscores on the CBI. Decreased affection $\left(r_{s}=-0.478, p=0.001\right)$, decreased response to affection $\left(r_{s}=-0.391\right.$, $p=0.006)$, decreased initiation $\left(r_{s}=-0.427\right.$, $p=0.003)$ and responsiveness $\left(r_{s}=-0.54, p=0.002\right)$, and frequency of sexual relations $\left(r_{s}=-0.477\right.$, $p=0.001)$ correlated with increased levels of stereotypical behavior on the CBI. On measures of aberrant sexual behavior, only disinhibited or childish like behavior regarding sex correlated with disinhibition on the NPI $\left(r_{s}=-0.505, p=0.005\right)$, whereby higher levels of disinhibition were associated with higher incidences of disinhibited sexual behavior. Change in sexual activities they wish to engage in, sexual interest in another person, and interest in pornography, voyeurism, chat lines, or prostitutes did not correlate with levels of disinhibition on the NPI.

\section{DISCUSSION}

This study is the first to systematically examine sexual behavior in FTD syndromes, and points to high rates of sexual dysfunction in patients with bvFTD compared to both SD and AD. Overwhelmingly, bvFTD patients showed hyposexual behavior, manifesting in decreases in sexual initiation, affection toward their partner, response to initiatives by their partner, and frequency of sexual relations compared to the AD group. Further, bvFTD patients displayed decreased response to initiatives by their partner and frequency of sexual relations compared to the SD group. The majority of the patients in the $\mathrm{AD}$ and SD groups also showed decreased initiation of sexual relations and frequency of sexual relations with their partners. The key differentiating factor between these groups and bvFTD, however, lies in their responding to sexual initiatives from their partner and their tendency to be affectionate and to accept affection from their partner.

Previous reports on sexual function $[11,12]$ in FTD have highlighted the occurrence of hypersexual and aberrant sexual behavior, yet the incidence of such behavior in these studies has been rather low, between $13 \%$ [12] and $17 \%$ [11]. In the current study, we found that bvFTD is characterized by hyposexual behavior that represents a change from their behavior prior to 
symptom onset. The bvFTD group showed the greatest changes in the domains of sexual initiation and affection compared to prior to behavioral symptom onset. These changes were most marked in the domains of initiating and responding to sexual advances and in frequency of sexual relations which approached a $100 \%$ decrease. In a proportion of patients (19\%), these changes occurred prior to other symptoms of bvFTD. The AD and SD groups also showed a decrease in affection and initiation and frequency of relations compared to prior to symptom onset, in contrast to the bvFTD group, however, these patients still responded to and liked to receive affection from their partner.

Of note is our finding that aberrant sexual behavior occurred in the minority of both bvFTD and SD patients. Three (of 11) SD patients (27\%) showed a change in the sexual behavior they wished to engage in, versus only 1 (of 21) patient (5\%) in the bvFTD group. For other measures of aberrant sexual behavior, the highest frequency was found in the bvFTD group for disinhibited or childish behavior regarding sex; this was found in 6 patients $(29 \%)$. One AD patient exhibited childish behavior regarding sex. Two bvFTD patients developed interest in another person, and 3 developed an interest in pornography, voyeurism, chat lines, or prostitutes, 2 of whom did not exhibit disinhibited behavior regarding sex. Despite showing aberrant sexual behavior, all of these patients showed decreased interest and hyposexual behavior toward their partner, and appeared to direct their interest toward external sources. This finding indicates that hyposexual behavior and aberrant sexual behavior can coexist.

The findings of hyposexuality in our FTD cohorts, particularly in the bvFTD group, contrasts with previous studies that have reported hypersexuality and aberrant sexual behavior in this syndrome [11, 12]. This difference may be due to the fact that these studies used retrospective case note review looking for documentation of hypersexual behavior and did not look for evidence of hyposexual behavior. It is notable that the one previous study which included caregiver interviews also found hyposexual behavior in the majority of bvFTD patients [13]. It may be that the emergence of aberrant and disinhibited sexual behaviors are more salient and disruptive to the caregiver in everyday life and thus overshadow the presence of hyposexual behaviors. We suggest that future studies examining the origin of aberrant and hypersexual behaviors versus hyposexual behaviors will be particularly important to clarify at what point in the disease trajectory these features typically emerge.
Hypersexual and aberrant sexual behavior has previously been suggested to arise from alterations in the right hemisphere reward pathways [11], and changes in sexual drive related to right anterior temporal limbic involvement $[12,15]$. As mentioned, one previous study has alluded to the presence of hyposexual behavior in FTD, with $54 \%$ of FTD caregivers reporting hyposexual behavior versus $23 \%$ in $\mathrm{AD}$ patients, and suggested that this may represent one of the first presenting symptoms of FTD [13]. Other studies have reported the rate of sexual changes in $\mathrm{AD}$ between $60-80 \%$ [28, 29] without changes in expression of affection [14]. Our findings suggest that hyposexual behavior, particularly in bvFTD, if not comparable, maybe even more prominent than that seen in $\mathrm{AD}$.

Findings from our study that the majority of bvFTD patients exhibited decreased drive and hyposexual behavior, with a minority showing aberrant sexual behavior, may be explained by considering the brain structures involved in sexual arousal [30]. Structures involved include the orbitofrontal cortex, anterior cingulate cortex, insula, amygdala, and subcortical structures including the thalamus and nucleus accumbens [31, 32], all of which are significantly compromised in bvFTD [33]. Further confounding the interpretation of the symptoms of hyposexuality in bvFTD patients, is the likely involvement of the hypothalamus and autonomic pathways, which has been implicated in the changes in appetite and food preference seen in bvFTD [4]. Case studies have suggested that focal lesions of the hypothalamus can lead to abolition of sexual drive, with lesions involving the hypothalamus and other structures such as the limbic network leading to a mixture of increased and decreased sexual drive, and abnormal behaviors [34].

Structures involved in inhibition of sexual arousal include the temporal cortex [30]. Hypersexual behavior has been described with tumors and strokes causing damage to the right temporo-limbic area [35, 36]. The concept that hypersexuality and aberrant sexual behavior may be related to damage to temporo-limbic structures $[35,36]$ is supported by our finding that the SD cohort showed the greatest change in sexual activities that they wish to engage in, which is potentially attributable to characteristic atrophy affecting the anterior temporal lobes [37]. It remains possible that the small percentage of bvFTD patients that show aberrant sexual behavior may have further damage extending into right temporo-limbic structures in addition to orbitofrontal atrophy [38].

In our study of the aberrant sexual behaviors measured, only disinhibited and childish comments about 
sex correlated to measures of disinhibition on the NPI. This suggests that factors other than disinhibition are associated with aberrant sexual behaviors. We also found that hyposexual behavior correlated with increased abnormal and stereotypical behavior as measured on the CBI, suggesting that the hyposexual behavior in part may be secondary to patients focusing on other obsessions and urges, for example eating. This may be due to patients seeking reward stimulation [11], at the expense of other behaviors and interactions, which has been suggested in bvFTD when patients, for example, crave music at the expense of interactions with people $[39,40]$.

One of the key findings in our study relates to the fact that the majority of patients in all groups show decreased sexual interest and hyposexuality, yet responses to initiatives and affection from their partner differs markedly between the dementia subtypes. The ability to respond to interpersonal cues, important for shared emotions and bonding, is selectively affected in bvFTD [5, 41], and likely plays a modulating role in sexual function. Alterations in empathy were significantly associated with lack of affection and decreased frequency of sexual relations in patients. Accordingly, damage to frontoinsular and anterior infero-lateral temporal cortices, typically observed in FTD syndromes, likely disrupts a core capacity to empathize and respond to the affection of others $[42,43]$. From a neuroendocrine perspective, oxytocin is known to be an important mediator of social behavior and emotional recognition, and an improvement in behavior in bvFTD patients has been suggested with administration of oxytocin [44]. Oxytocin through interactions with gonadal hormones has also been suggested to affect sexual function [45], with decreased levels or action potentially producing decreased sexual drive. When bvFTD patients are administered oxytocin a proportion develop hypersexual behavior [46]. As such, it is possible that neuroendocrine abnormalities modulate hyposexual behavior, and this proposal requires further investigation.

A second contributing factor that may account for decreased sexual initiation and affection and response to advances by caregivers is a general loss of motivation, as typically observed in bvFTD [47]. Our finding of significant associations between decreased motivation on the CBI and decreased sexual initiation offers strong support for this position. Apathy (decreased motivation) has been suggested to reflect damage to the right dorsolateral prefrontal cortex [48], which likely disrupts the functional integrity of frontal and hypothalamic regions [49], thus promoting hyposexual function. Our findings converge to suggest that causes of sexual dysfunction in FTD patients are multifactorial and could reflect neuroendocrine disruption, as well as the degradation of multiple brain regions responsible for interpersonal warmth, responding to emotional cues, and overall levels of motivation and empathy.

Given that changes in sexual behavior occurred prior to other symptoms of bvFTD in a proportion of our patients, and hyposexuality has also previously being suggested to occur prior to cognitive symptoms [13], future studies could examine for the presence of changes in sexual behavior in genetic at-risk populations. Future studies using a larger population could also examine the effect of the normal process of aging on sexual function and the differences in sexual function between both right and left variant SD patients, given the characteristic changes in socioemotional behaviors typically seen in right-sided SD cases [50].

In the majority of our bvFTD group $(60 \%)$, caregivers felt that changes in sexual behavior had not had an effect on their relationship, while $40 \%$ rated changes as having a negative effect. This finding suggests that some caregivers may have adapted to a different role within the relationship (i.e., from romantic partner to caregiver) and potentially experience a change in their own expectations and interest in intimacy. Further in depth studies on the effects of sexual function on caregiver burden, and sense of self are required in this context.

While development of aberrant sexual behavior may alert the clinician to a diagnosis of bvFTD, this symptom has a high specificity but low sensitivity. In contrast, overall loss of affection, reduced initiation of sexual activity, and responsiveness represent overwhelming features of bvFTD. These changes are likely to reflect the degeneration of multiple regions in the brain, and likely contribute to the high levels of burden and stress shown by partners of patients with bvFTD [51]. We suspect that few clinicians enquire about sexual function, and propose that enquiring regarding this core feature of FTD should form an important part of routine diagnostic interviews in an effort to further understand the origins of this dramatic behavioral change and to provide information and support for caregivers.

\section{ACKNOWLEDGMENTS}

Rebekah Ahmed and John Hodges had full access to all of the data in the study and take responsibility for 
the integrity of the data and the accuracy of the data analysis

This work was supported by funding to Forefront, a collaborative research group dedicated to the study of frontotemporal dementia and motor neurone disease, from the National Health and Medical Research Council of Australia (NHMRC) program grant (\#1037746) and the Australian Research Council Centre of Excellence in Cognition and its Disorders Memory Node (\#CE110001021) and other grants/sources (NHMRC project grant \#1003139). RA is a Royal Australasian College of Physicians PhD scholar and MND Australia PhD scholar. OP is an NHMRC Career Development Research Fellow (\#1022684). MI is supported by an Australian Research Council Discovery Early Career Researcher Award (DE130100463). No funding organization had a role in design and conduct of the study; collection, management, analysis, and interpretation of the data; and preparation, review, or approval of the manuscript; and decision to submit the manuscript for publication

Authors' disclosures available online (http://j-alz. com/manuscript-disclosures/15-0034r2).

\section{SUPPLEMENTARY MATERIAL}

The supplementary material is available in the electronic version of this article: http://dx.doi.org/ 10.3233/JAD-150034.

\section{REFERENCES}

[1] Ratnavalli E, Brayne C, Dawson K, Hodges JR (2002) The prevalence of frontotemporal dementia. Neurology 58, 16151621.

[2] Rosso SM, Donker Kaat L, Baks T, Joosse M, de Koning I, Pijnenburg Y, de Jong D, Dooijes D, Kamphorst W, Ravid R, Niermeijer MF, Verheij F, Kremer HP, Scheltens P, van Duijn CM, Heutink P, van Swieten JC (2003) Frontotemporal dementia in The Netherlands: Patient characteristics and prevalence estimates from a population-based study. Brain 126, 2016-2022.

[3] Ahmed RM, Irish M, Kam J, van Keizerswaard J, Bartley L, Samaras K, Hodges JR, Piguet O (2014) Quantifying the eating abnormalities in frontotemporal dementia. JAMA Neurol 71, 1540-1546.

[4] Piguet O, Petersen A, Yin Ka Lam B, Gabery S, Murphy K, Hodges JR, Halliday GM (2011) Eating and hypothalamus changes in behavioral-variant frontotemporal dementia. Ann Neurol 69, 312-319.

[5] Kumfor F, Irish M, Leyton C, Miller L, Lah S, Devenney E, Hodges JR, Piguet O (2014) Tracking the progression of social cognition in neurodegenerative disorders. J Neurol Neurosurg Psychiatry 85, 1076-1083.

[6] Bonakis A, Economou NT, Paparrigopoulos T, Bonanni E, Maestri M, Carnicelli L, Di Coscio E, Ktonas P, Vagiakis E, Theodoropoulos P, Papageorgiou SG (2014) Sleep in frontotemporal dementia is equally or possibly more disrupted, and at an earlier stage, when compared to sleep in Alzheimer's disease. J Alzheimers Dis 38, 85-91.

[7] Hornberger M, Geng J, Hodges JR (2011) Convergent grey and white matter evidence of orbitofrontal cortex changes related to disinhibition in behavioural variant frontotemporal dementia. Brain 134, 2502-2512.

[8] Poetter CE, Stewart JT (2012) Treatment of indiscriminate, inappropriate sexual behavior in frontotemporal dementia with carbamazepine. J Clin Psychopharmacol 32, 137-138.

[9] Mendez MF, Shapira JS (2011) Internet pornography and frontotemporal dementia. J Neuropsychiatry Clin Neurosci 23, E3.

[10] Reeves RR, Perry CL (2013) Aripiprazole for sexually inappropriate vocalizations in frontotemporal dementia. J Clin Psychopharmacol 33, 145-146.

[11] Perry DC, Sturm VE, Seeley WW, Miller BL, Kramer JH, Rosen HJ (2014) Anatomical correlates of reward-seeking behaviours in behavioural variant frontotemporal dementia. Brain 137, 1621-1626.

[12] Mendez MF, Shapira JS (2013) Hypersexual behavior in frontotemporal dementia: A comparison with early-onset Alzheimer's disease. Arch Sex Behav 42, 501-509.

[13] Miller BL, Darby AL, Swartz JR, Yener GG, Mena I (1995) Dietary changes, compulsions and sexual behavior in frontotemporal degeneration. Dementia 6, 195-199.

[14] Wright LK (1991) The impact of Alzheimer's disease on the marital relationship. Gerontologist 31, 224-237.

[15] Black B, Muralee S, Tampi RR (2005) Inappropriate sexual behaviors in dementia. J Geriatr Psychiatry Neurol 18, 155162.

[16] Gorno-Tempini ML, Hillis AE, Weintraub S, Kertesz A, Mendez M, Cappa SF, Ogar JM, Rohrer JD, Black S, Boeve BF, Manes F, Dronkers NF, Vandenberghe R, Rascovsky K, Patterson K, Miller BL, Knopman DS, Hodges JR, Mesulam MM, Grossman M (2011) Classification of primary progressive aphasia and its variants. Neurology $\mathbf{7 6}$, 1006-1014.

[17] Rascovsky K, Hodges JR, Knopman D, Mendez MF, Kramer JH, Neuhaus J, van Swieten JC, Seelaar H, Dopper EG, Onyike CU, Hillis AE, Josephs KA, Boeve BF, Kertesz A, Seeley WW, Rankin KP, Johnson JK, Gorno-Tempini ML, Rosen H, Prioleau-Latham CE, Lee A, Kipps CM, Lillo $\mathrm{P}$, Piguet O, Rohrer JD, Rossor MN, Warren JD, Fox NC, Galasko D, Salmon DP, Black SE, Mesulam M, Weintraub S, Dickerson BC, Diehl-Schmid J, Pasquier F, Deramecourt V, Lebert F, Pijnenburg Y, Chow TW, Manes F, Grafman J, Cappa SF, Freedman M, Grossman M, Miller BL (2011) Sensitivity of revised diagnostic criteria for the behavioural variant of frontotemporal dementia. Brain 134, 2456-2477.

[18] McKhann GM, Albert MS, Grossman M, Miller B, Dickson D, Trojanowski JQ, Work Group on Frontotemporal Dementia and Pick's Disease (2001) Clinical and pathological diagnosis of frontotemporal dementia: Report of the Work Group on Frontotemporal Dementia and Pick's Disease. Arch Neurol 58, 1803-1809.

[19] McKhann GM, Knopman DS, Chertkow H, Hyman BT, Jack CR Jr, Kawas CH, Klunk WE, Koroshetz WJ, Manly JJ, Mayeux R, Mohs RC, Morris JC, Rossor MN, Scheltens P, Carrillo MC, Thies B, Weintraub S, Phelps $\mathrm{CH}$ (2011) The diagnosis of dementia due to Alzheimer's disease: Recommendations from the National Institute on Aging-Alzheimer's Association workgroups on diagnostic guidelines for Alzheimer's disease. Alzheimers Dement 7, 263-269. 
[20] Mioshi E, Hsieh S, Savage S, Hornberger M, Hodges JR (2010) Clinical staging and disease progression in frontotemporal dementia. Neurology 74, 1591-1597.

[21] Bozeat S, Gregory CA, Ralph MA, Hodges JR (2000) Which neuropsychiatric and behavioural features distinguish frontal and temporal variants of frontotemporal dementia from Alzheimer's disease? J Neurol Neurosurg Psychiatry 69, 178-186.

[22] Davis M (1983) Measuring individual differences in empathy: Evidence for a multidimensional approach. J Pers Soc Psychol 44, 113-126.

[23] Cummings JL, Mega M, Gray K, Rosenberg-Thompson S, Carusi DA, Gornbein J (1994) The Neuropsychiatric Inventory: Comprehensive assessment of psychopathology in dementia. Neurology 44, 2308-2314.

[24] Mioshi E, Dawson K, Mitchell J, Arnold R, Hodges JR (2006) The Addenbrooke's Cognitive Examination Revised (ACER): A brief cognitive test battery for dementia screening. Int J Geriatr Psychiatry 21, 1078-1085.

[25] Morris LW, Morris RG, Britton PG (1988) The relationship between marital intimacy, perceived strain and depression in spouse caregivers of dementia sufferers. Br J Med Psychol 61(Pt 3), 231-236.

[26] Rust J, Golombok S (1985) The Golombok-Rust Inventory of Sexual Satisfaction (GRISS). Br J Clin Psychol 24(Pt 1), 63-64.

[27] Kravetz S, Drory Y, Snaked A (1999) The Israeli Sexual Behavior Inventory (ISBI): Scale construction and preliminary validation. Sex Disab 17, 115-128.

[28] Eloniemi-Sulkava U, Notkola IL, Hamalainen K, Rahkonen T, Viramo P, Hentinen M, Kivela SL, Sulkava R (2002) Spouse caregivers' perceptions of influence of dementia on marriage. Int Psychogeriatr 14, 47-58.

[29] Simonelli C, Tripodi F, Rossi R, Fabrizi A, Lembo D, Cosmi V, Pierleoni L (2008) The influence of caregiver burden on sexual intimacy and marital satisfaction in couples with an Alzheimer spouse. Int J Clin Pract 62, 47-52.

[30] Rees PM, Fowler CJ, Maas CP (2007) Sexual function in men and women with neurological disorders. Lancet 369, 512-525.

[31] Arnow BA, Desmond JE, Banner LL, Glover GH, Solomon A, Polan ML, Lue TF, Atlas SW (2002) Brain activation and sexual arousal in healthy, heterosexual males. Brain 125, 1014-1023.

[32] Karama S, Lecours AR, Leroux JM, Bourgouin P, Beaudoin G, Joubert S, Beauregard M (2002) Areas of brain activation in males and females during viewing of erotic film excerpts. Hum Brain Mapp 16, 1-13.

[33] Hornberger M, Savage S, Hsieh S, Mioshi E, Piguet O, Hodges JR (2010) Orbitofrontal dysfunction discriminates behavioral variant frontotemporal dementia from Alzheimer's disease. Dement Geriatr Cogn Disord 30, 547-552.

[34] Baird AD, Wilson SJ, Bladin PF, Saling MM, Reutens DC (2007) Neurological control of human sexual behaviour: Insights from lesion studies. J Neurol Neurosurg Psychiatry 78, 1042-1049.

[35] Baird AD, Wilson SJ, Bladin PF, Saling MM, Reutens DC (2004) The amygdala and sexual drive: Insights from temporal lobe epilepsy surgery. Ann Neurol 55, 87-96.

[36] Braun CM, Dumont M, Duval J, Hamel I, Godbout L (2003) Opposed left and right brain hemisphere contributions to sexual drive: A multiple lesion case analysis. Behav Neurol 14, 55-61.

[37] Rosen HJ, Gorno-Tempini ML, Goldman WP, Perry RJ, Schuff N, Weiner M, Feiwell R, Kramer JH, Miller BL (2002) Patterns of brain atrophy in frontotemporal dementia and semantic dementia. Neurology 58, 198-208.

[38] Rabinovici GD, Seeley WW, Kim EJ, Gorno-Tempini ML, Rascovsky K, Pagliaro TA, Allison SC, Halabi C, Kramer JH, Johnson JK, Weiner MW, Forman MS, Trojanowski JQ, Dearmond SJ, Miller BL, Rosen HJ (2007) Distinct MRI atrophy patterns in autopsy-proven Alzheimer's disease and frontotemporal lobar degeneration. Am J Alzheimers Dis Other Demen 22, 474-488.

[39] Fletcher PD, Clark CN, Warren JD (2014) Music, reward and frontotemporal dementia. Brain 137, e300.

[40] Fletcher PD, Downey LE, Witoonpanich P, Warren JD (2013) The brain basis of musicophilia: Evidence from frontotemporal lobar degeneration. Front Psychol 4, 347.

[41] Kumfor F, Irish M, Hodges JR, Piguet O (2013) Discrete neural correlates for the recognition of negative emotions: Insights from frontotemporal dementia. PLoS One 8, e67457.

[42] Irish M, Piguet O, Hodges JR (2011) Self-projection and the default network in frontotemporal dementia. Nat Rev Neurol 8, 152-161.

[43] Sollberger M, Rosen HJ, Shany-Ur T, Ullah J, Stanley CM, Laluz V, Weiner MW, Wilson SM, Miller BL, Rankin KP (2014) Neural substrates of socioemotional self-awareness in neurodegenerative disease. Brain Behav 4, 201-214.

[44] Jesso S, Morlog D, Ross S, Pell MD, Pasternak SH, Mitchell DG, Kertesz A, Finger EC (2011) The effects of oxytocin on social cognition and behaviour in frontotemporal dementia. Brain 134, 2493-2501.

[45] Macdonald KS (2012) Sex, receptors, and attachment: A review of individual factors influencing response to oxytocin. Front Neurosci 6, 194.

[46] Finger EC, MacKinley J, Blair M, Oliver LD, Jesso S, Tartaglia MC, Borrie M, Wells J, Dziobek I, Pasternak S, Mitchell DG, Rankin K, Kertesz A, Boxer A (2015) Oxytocin for frontotemporal dementia: A randomized dose-finding study of safety and tolerability. Neurology 84, 174-181.

[47] Eslinger PJ, Moore P, Antani S, Anderson C, Grossman M (2012) Apathy in frontotemporal dementia: Behavioral and neuroimaging correlates. Behav Neurol 25, 127-136.

[48] Zamboni G, Huey ED, Krueger F, Nichelli PF, Grafman J (2008) Apathy and disinhibition in frontotemporal dementia: Insights into their neural correlates. Neurology 71, 736-742.

[49] Kullmann S, Heni M, Linder K, Zipfel S, Haring HU, Veit R, Fritsche A, Preissl H (2014) Resting-state functional connectivity of the human hypothalamus. Hum Brain Mapp 35, 6088-6096.

[50] Kamminga J, Kumfor F, Burrell JR, Piguet O, Hodges JR, Irish M (2014) Differentiating between right-lateralised semantic dementia and behavioural-variant frontotemporal dementia: An examination of clinical characteristics and emotion processing. J Neurol Neurosurg Psychiatry. 2014 Dec 15. pii: jnnp-2014-309120. doi: 10.1136/jnnp-2014-309120. [Epub ahead of print]

[51] Mioshi E, Bristow M, Cook R, Hodges JR (2009) Factors underlying caregiver stress in frontotemporal dementia and Alzheimer's disease. Dement Geriatr Cogn Disord 27, 76-81. 